\title{
Comportamento ingestivo de vacas leiteiras em pastagem de azevém alimentadas com diferentes fontes proteicas
}

\author{
[Ingestive behavior of dairy cows in annual ryegrass pasture, fed with different proteic sources]

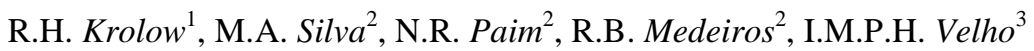 \\ ${ }^{1}$ Unipampa - Campus Uruguaiana, RS \\ ${ }^{2}$ Faculdade de Agronomia - Universidade Federal do Rio Grande do Sul -UFRGS - Porto Alegre, RS \\ ${ }^{3}$ Escola Estadual Técnica Celeste Gobbato - Palmeira das Missões, RS
}

\begin{abstract}
RESUMO
Estudou-se o efeito da substituição do farelo de soja da ração por pastejo controlado de trevo-branco (Trifolium repens L.) sobre o comportamento ingestivo de vacas da raça Holandesa em pastejo de azevém (Lolium multiflorum Lam.). Utilizaram-se dois grupos de animais, com média de 20 vacas agrupadas por produção, período de lactação e peso corporal, em delineamento experimental em blocos ao acaso. Um grupo recebeu, diariamente, $3 \mathrm{~kg}$ de suplemento energético e teve acesso controlado à pastagem de trevobranco por aproximadamente duas horas e meia (TB); o outro recebeu o mesmo suplemento, adicionado de quantidade de proteína equivalente ao consumo diário no tratamento anterior via trevo, na forma de farelo de soja (FS). Para a avaliação de comportamento, procedeu-se à observação e ao registro do ritmo de atividade dos animais, no período de pastejo em azevém durante dois dias consecutivos, quinzenalmente. Observou-se maior tempo de pastejo em minutos (min), 212,00 versus 194,24min $\mathrm{dia}^{-1}$, e frequência de bocados (bocado), 67,78 versus 64,09 bocado $\mathrm{min}^{-1}$, entre os animais do tratamento FS, em relação ao TB. Não houve diferença no consumo de azevém entre os tratamentos, com valores de 3,65 e $4,11 \mathrm{~kg} \mathrm{vaca}^{-1}$ dia $^{-1}$ de matéria seca para TB e FS, respectivamente, o que sugere adequada adaptação dos animais às duas situações estudadas.
\end{abstract}

Palavras-chave: bovino leiteiro, frequência de bocados, pastejo, tempo de pastejo

\begin{abstract}
The effect of the replacement of soybean meal in the ration with controlled grazing of white clover (Trifolium repens L.) on the ingestive behavior of cows of the holstein breed grazing on annual ryegrass (Lolium multiflorum Lam.) was studied. Two groups of animals with an average of 20 cows grouped by production, lactation period and body weight were used in a randomized block experimental design. One group received $3 \mathrm{~kg}$ from energy supplement daily and had controlled access to the white clover pasture for approximately 2.5 hours (TB); the other received the same supplement, added of a quantity of protein equivalent to daily intake in previous treatment via white clover, in the form of soybean meal (FS). For behavior assessment the observation and recording of the rhythm of activity of the animals, during the grazing period in ryegrass for two consecutive days, fortnightly was done. The longest grazing time in

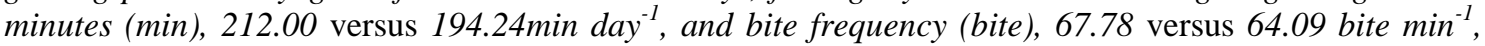
between the animals from treatment FS, when compared to TB was observed. There was no difference in the intake of ryegrass between the treatments, with values of 3.65 and $4.11 \mathrm{~kg} \mathrm{cow}^{-1}$ day ${ }^{-1}$ of dry matter for $T B$ and FS, respectively, suggesting adequate adaptation of the animals in the two situations studied.
\end{abstract}

Keywords: dairy cattle, bite frequency, grazing, grazing time

Recebido em 19 de julho de 2012

Aceito em 20 de dezembro de 2013

E-mail: rodrigokrolow@unipampa.edu.br

Apoio financeiro: CNPq e Prefeitura Municipal de Camargo, RS 


\section{INTRODUÇÃO}

A inclusão de alimentos energéticos e proteicos em misturas concentradas é uma prática comum em sistemas de produção especializados, pois melhora o desempenho de vacas de alta produção de leite. Porém, a manipulação da dieta com diferentes ingredientes ou subprodutos, com intuito de alterar a produção e a composição do leite, tornou-se uma prática comum na atividade leiteira (Oliveira et al., 2007).

A crescente demanda pela utilização racional e sustentável dos alimentos exerce uma pressão cada vez maior sobre a pesquisa e a utilização de fontes alimentícias alternativas na nutrição. A busca por alternativas para substituir os grãos na alimentação de ruminantes em produção assume grande importância (Pedroso et al., 2009). O custo de fontes tradicionais de alimentos constitui um fator limitante dos sistemas de produção, e a inclusão de fontes proteicas alternativas na alimentação de vacas tem como principal objetivo baixar os custos e manter o desempenho animal. A correta utilização dos suplementos proteicos tem um impacto considerável na rentabilidade do negócio, pois as diferentes fontes de proteína representam parcela considerável do custo das dietas para vacas em lactação (Imaizumi et al., 2010).

A utilização de outras fontes proteicas em substituição ao farelo de soja - a principal fonte proteica para vacas leiteiras suplementadas com concentrado -, desde que não comprometa o desempenho animal, pode ser uma estratégia viável para a redução dos custos dietéticos do rebanho leiteiro. No entanto, essas fontes proteicas alternativas devem ser eficientes, seguras e econômicas, e permitir desempenho similar aos de animais alimentados com dietas tradicionais (Pina et al., 2006). Além disso, o estudo do comportamento ingestivo dos ruminantes pode nortear a adequação de sistemas que venham a aumentar a produtividade $\mathrm{e}$ garantir o melhor estado sanitário e a maior longevidade aos animais (Mendonça et al., 2004).

O comportamento ingestivo tem sido estudado com relação às características dos alimentos. Esses estudos servem como avaliação das dietas e possibilitam ajustar o manejo alimentar de diferentes categorias, para obtenção de maior produção (Mendonça et al., 2004). Grant e Albright (2000), em extensa revisão, concluíram que o modelo do sistema de alimentação, a composição e as características físicas do alimento consumido influenciam o comportamento alimentar do gado. O tipo de suplemento (Pereira et al., 2005) e sua quantidade (Patiño Pardo et al., 2003) podem influenciar o comportamento e o consumo alimentar, bem como o aproveitamento da pastagem.

Os estudos realizados normalmente referem-se às pesquisas feitas no exterior, e poucas dessas enfocam o estudo do comportamento animal em pastejo, com espécies forrageiras de clima temperado, em nosso meio. Neste sentido, realizou-se este trabalho com o objetivo de estudar o comportamento de vacas leiteiras da raça Holandesa em pastagens de azevém, com a utilização de duas fontes de alimento proteico na alimentação dos animais.

\section{MATERIAL E MÉTODOS}

O trabalho foi desenvolvido em um estabelecimento particular de pecuária leiteira, localizado no município de Camargo, na bacia leiteira de Passo Fundo - Marau, RS. Na região, as temperaturas médias estão entre 16 e $18^{\circ} \mathrm{C}$, as médias das máximas entre 22 e $25^{\circ} \mathrm{C}$ e das mínimas entre 10 e $13^{\circ} \mathrm{C}$ (IPAGRO, 1989). A precipitação pluvial apresenta-se bem distribuída ao longo do ano, e o inverno é marcado por fortes geadas e eventuais nevascas.

Foram utilizadas áreas de pastagens da propriedade, cultivadas com azevém anual (Lolium multiflorum Lam.), proveniente de ressemeadura natural, muito comum e usual na região de estudo, e trevo-branco (Trifolium repens L.), implantado no ano anterior. Procedeu-se à adubação na área de trevo-branco, para a reposição de nutrientes, conforme a recomendação obtida pela análise do solo. $\mathrm{Na}$ área de azevém, após cada período de pastejo foram aplicados $50 \mathrm{~kg}$ de ureia $\mathrm{ha}^{-1}$.

Utilizaram-se vacas da raça Holandesa, escolhidas no rebanho da propriedade em função da produção de leite, do período de lactação e do peso vivo individual. Após a estratificação com base nesses três quesitos, os animais foram distribuídos ao acaso, em dois grupos, com 20 
animais em média, distribuídos de forma aleatória em dois tratamentos e mantidos durante todo o experimento em piquetes separados.

Em um dos tratamentos (TB), os animais foram mantidos em pastagem de azevém, por determinado tempo, durante o dia - \pm cinco horas -, e com acesso controlado à pastagem de trevobranco - \pm duas horas e meia - como fonte de alimentação proteica; no outro tratamento (FS), foram mantidos em pastagem de azevém pelo mesmo período e receberam farelo de soja como fonte proteica - na quantidade de $1,6 \mathrm{~kg}$ animal $^{-1}$ $\mathrm{dia}^{-1}$ - calculada pela estimativa do consumo diário de proteína pelos animais no tratamento anterior via trevo-branco, considerando-se o teor de proteína e a digestibilidade do trevo e do farelo. Todos os animais receberam suplementação energética $-3 \mathrm{~kg}$ animal ${ }^{-1} \mathrm{dia}^{-1}$ constituída de farelo de trigo, farelo de milho, casca de soja e sal mineral. Esse procedimento visou comparar uma fonte alternativa de alimento proteico - o TB - com um sistema controle - o FS -, que reproduz, em sua quase totalidade, o modelo tecnológico adotado pela propriedade e comumente utilizado na região pela maioria dos produtores de leite.

Os animais foram submetidos, previamente, a um período de 15 dias de adaptação ao manejo nutricional utilizado durante o período experimental, que perdurou de agosto a outubro de 2004, totalizando cinco períodos de avaliação, realizado a cada 15 dias, em delineamento em blocos ao acaso. Foram utilizados como critério de bloqueamento os períodos de avaliações, devido às possíveis diferenças em relação a fatores climáticos ou mudança de estádio fenológico da pastagem, dado ao grande período do experimento.

Adotou-se o pastejo rotativo em faixas utilizadas por um dia, seguindo o manejo normal da propriedade, realizada da seguinte maneira: após a ordenha da manhã, os animais eram conduzidos à pastagem de azevém, onde permaneciam por aproximadamente cinco horas. Os dois lotes de animais permaneciam afastados em uma distância mínima de 30 metros, a fim de se minimizar a interferência de comportamento em pastejo entre eles. Após este período, eram conduzidos a um local onde tinham acesso à água e sombra. Os animais do tratamento FS ali permaneciam, enquanto os do TB eram levados até a pastagem de trevo-branco, onde permaneciam por, aproximadamente, duas horas e meia, até a ordenha da parte da tarde. Na sequência, todos pernoitavam em um galpão. $\mathrm{O}$ tempo de permanência de duas horas e meia foi determinado em função do tamanho da área disponível de trevo-branco destinada ao pastejo do grupo de animais.

Procurou-se manter a disponibilidade de forragem, na entrada e na saída dos animais de cada piquete, diariamente, a fim de otimizar a utilização subsequente e prolongar, ao máximo, o período de uso da pastagem, baseando-se, principalmente, na altura do resíduo. A disponibilidade média na pastagem de azevém manteve-se em 1271,20 e $1099,00 \mathrm{~kg} \mathrm{ha}^{-1}$ na entrada e 563,68 e $385,50 \mathrm{~kg} \mathrm{ha}^{-1}$ na saída dos animais para TB e FS, respectivamente.

Para a determinação da disponibilidade de entrada e saída diária, usou-se o método da dupla amostragem por meio de cortes e utilização do disco graduado medidor de forragem (Santillan et al., 1979). Para estimar a disponibilidade de forragem, no início e no final de cada período, usaram-se 20 amostras, cortadas acima do nível do solo $- \pm 5 \mathrm{~cm}-$, de forma a buscar a melhor representatividade da área, e em torno de 120 leituras com o disco medidor. Das 20 amostras, cinco, escolhidas ao acaso, após a retirada das amostras com maior e menor peso de matéria verde (MV), foram utilizadas para avaliação qualitativa da pastagem por separação botânica. Após a amostragem e a separação botânica, observou-se que as amostras obtidas na pastagem de trevo-branco continham, em média, 80,42g $100 \mathrm{~g}^{-1}$ de MV da espécie trevo-branco. Após a separação, os componentes acondicionados, juntamente com o restante das amostras, foram levados para secagem em estufa de circulação de ar a $65^{\circ} \mathrm{C}$ por $72 \mathrm{~h}$, para a determinação da matéria seca (MS).

O consumo diário de MS por animal foi estimado por cálculo de diferença entre a MS de folhas verdes - obtida por meio de simulação de pastejo - para o azevém e a MS total para o trevobranco, disponível antes e após o pastejo, descontando-se as perdas por amassamento por pisoteio ou material rejeitado. Procedeu-se à simulação de pastejo individual dos animais na pastagem de azevém para estimar a qualidade do material ingerido e, assim, determinar a 
porcentagem de folhas verdes de azevém contidas neste.

A avaliação comportamental - ritmo de atividades e frequência de bocados - foi realizada quinzenalmente, durante dois dias consecutivos. O ritmo de atividades dos animais foi determinado com base em registros, realizados a cada 10 minutos (min), por meio de observações visuais durante todo o período em que os animais permaneciam na pastagem de azevém - \pm cinco horas - , onde era registrada a quantidade de animais em cada uma das seguintes atividades: parado, deitado, caminhando e pastejando. Assim, obtiveram-se, ao final de cada período de pastejo, perfis descritivos das diferentes atividades que compõem o ritmo cotidiano de atividades do rebanho. A variável tempo de pastejo (TP) foi calculada pela integração dos perfis descritivos da atividade de pastejo, após padronização do tempo de permanência dos animais na pastagem, entre os diferentes períodos de avaliação. Dessa forma, o tempo total de pastejo efetivo resultou do somatório dos valores calculados para cada intervalo de 10 minutos.

A determinação da frequência de bocados foi efetuada durante o período de permanência dos animais na pastagem, em cada intervalo de 10 minutos, por meio do método do tempo de vinte bocados (Jamieson e Hodgson, 1979), realizando-se, posteriormente, a conversão dos valores obtidos para número de bocados (bocado) por minuto.

Os dados obtidos foram submetidos à análise multivariada, utilizando-se o programa estatístico Multiv (Pillar, 2006). Com base nos dados médios de cinco avaliações e em uma matriz de dados com 20 unidades para as variáveis frequência de bocados e tempo de pastejo e 10 unidades para consumo de azevém, a diferença entre os tratamentos foi testada mediante análise de variância de dados quantitativos, com testes de aleatorização para estimar a significância e 10000 iterações. A medida de semelhança utilizada foi a distância euclidiana entre unidades amostrais.

\section{RESULTADOS E DISCUSSÃO}

Observou-se diferença $(\mathrm{P}=0,008)$ para tempo de pastejo entre os tratamentos. Em média, nos cinco períodos de avaliação, ocorreu maior tempo de pastejo de animais que receberam farelo de soja como fonte proteica (Tab. 1).

Tabela 1. Comportamento animal em pastagem de azevém, nos tratamentos trevo- branco (TB) e farelo de soja (FS), no período de agosto a outubro de 2004

\begin{tabular}{|c|c|c|c|c|}
\hline \multirow{2}{*}{ Avaliação } & \multicolumn{2}{|c|}{$\begin{array}{l}\text {-----Tempo de pastejo----- } \\
\qquad\left(\min \operatorname{dia}^{-1}\right)^{(1)}\end{array}$} & \multicolumn{2}{|c|}{ 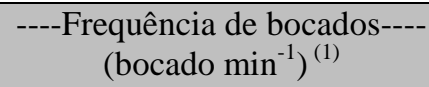 } \\
\hline & TB & FS & TB & FS \\
\hline $24 / 08$ & 186,83 & 217,08 & 68,72 & 64,86 \\
\hline 07/09 & 209,01 & 196,69 & 59,07 & 65,70 \\
\hline $21 / 09$ & 192,37 & 214,93 & 65,56 & 71,49 \\
\hline $05 / 10$ & 198,25 & 226,18 & 67,05 & 71,25 \\
\hline $20 / 10$ & 184,75 & 205,13 & 60,06 & 65,59 \\
\hline Médias & $194,24 b$ & $212,00 \mathrm{a}$ & $64,09 \mathrm{~b}$ & $67,78 \mathrm{a}$ \\
\hline
\end{tabular}

Médias seguidas por letras distintas na linha diferem entre si.

${ }^{(1)}$ Médias de dois dias consecutivos de observação de comportamento.

Esta resposta deve-se ao fato de que os animais no $\mathrm{TB}$ tiveram acesso às pastagens de trevo e de azevém e, assim, ao final do dia, tiveram mais tempo de acesso às pastagens e alimentação pelo pastejo. Esta diferença ocorreu em razão de o suplemento proteico ser composto por farelo de soja, um alimento de alta degradabilidade ruminal, com baixa quantidade de carboidratos estruturais e de fácil digestão. $\mathrm{O}$ aumento no teor de MS consumida na pastagem de trevo, e assim o de fibra, e a diminuição no teor de proteína bruta e digestibilidade, contribuíram para a diminuição no tempo de pastejo do TB. Quando se reduz o valor nutricional da alimentação, o tempo de pastejo diminui e o de ruminação aumenta, o que pode competir com o tempo destinado ao pastejo, pois sabe-se que o tempo de ruminação é influenciado pela natureza da 
dieta e é proporcional ao teor de parede celular do volumoso. Este, quando é elevado, tende a aumentar o tempo de ruminação (Van Soest, 1994). As relações entre o alimento e o animal podem influenciar o comportamento ingestivo e modificar o tempo destinado às atividades de pastejo, ruminação e ócio (Bargo et al., 2003). Não apenas o teor de fibra em detergente neutro (FDN) altera o tempo gasto com a ruminação, mas também a qualidade da FDN e a sua degradabilidade ruminal efetiva (Mendonça et al., 2004).

Para a variável frequência de bocados, houve diferença entre os tratamentos $(\mathrm{P}=0,015)$. $\mathrm{O}$ número de bocados por minuto foi maior entre os animais do FS, em comparação ao TB (Tab. 1). Semelhantemente ao ocorrido com o tempo de pastejo, a frequência de bocados foi maior entre os animais que não tiveram acesso à pastagem de trevo-branco.

$\mathrm{Na}$ literatura é consenso que os animais modulam seu tempo de permanência em pastejo e a frequência de bocados, para compensar deficiências na alimentação, principalmente quando há diferenças na pastagem em termos de disponibilidade ou qualidade da forragem. O hábito de pastejo pode variar em função de fatores nutricionais que incluem o preenchimento do rúmen, a proporção de ácido acético ruminal ou a demanda por nutrientes, o que, por meio do sistema nervoso central, ocasiona o início ou o término da alimentação (Curtis e Houpt, 1983). Assim sendo, há a hipótese de que: a restrição de acesso à pastagem imposta aos animais do FS teria originado menor ingestão de MS, responsável pela modulação de seu comportamento, via aumento do tempo de pastejo e da frequência de bocados, com vistas ao aumento do consumo de MS. À medida que o consumo de volumoso diminui, frequentemente a frequência de bocados e o tempo de pastejo dos animais aumentam (Gontijo Neto et al., 2006).

O consumo de MS total de trevo-branco, nos diferentes períodos de avaliação, é apresentado na Tab. 2.

Tabela 2. Consumo médio de trevo-branco no tratamento trevo-branco (TB), no período de agosto a outubro de 2004

\begin{tabular}{|c|c|c|c|c|c|c|c|}
\hline \multirow[b]{2}{*}{ Tratamento } & \multicolumn{6}{|c|}{ 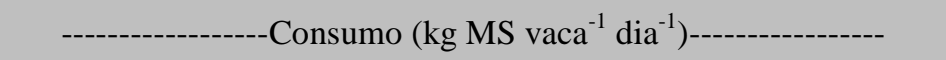 } & \multirow[b]{2}{*}{ Média } \\
\hline & $09 / 08$ & $22 / 08$ & $05 / 09$ & $19 / 09$ & $03 / 10$ & $18 / 10$ & \\
\hline $\mathrm{TB}$ & 7,31 & 3,44 & 2,07 & 4,61 & 4,85 & 6,15 & 4,74 \\
\hline
\end{tabular}

$\mathrm{Na}$ Tab. 3, encontram-se os valores referentes ao consumo de MS de folhas verdes de azevém variável que está intimamente relacionada à produção -, determinado pela simulação de pastejo, para os dois tratamentos. Não houve diferença entre os tratamentos $(\mathrm{P}=0,612)$.

Tabela 3. Consumo médio de folhas verdes de azevém nos tratamentos trevo-branco (TB) e farelo de soja (FS), no período de agosto a outubro de 2004

\begin{tabular}{ccccccc} 
& \multicolumn{7}{c}{- ----- Consumo $\left(\mathrm{kg}\right.$ MS folhas verdes vaca ${ }^{-1} \mathrm{dia}^{-1}$ ) } & & \\
Tratamento & $22 / 08$ & $05 / 09$ & $19 / 09$ & $03 / 10$ & $18 / 10$ & Média $^{1}$ \\
\hline TB & 5,73 & 5,33 & 1,51 & 3,59 & 2,10 & 3,65 \\
FS & 6,22 & 5,11 & 5,02 & 1,78 & 2,40 & 4,11 \\
\hline
\end{tabular}

${ }^{\mathrm{T}}$ Não houve diferença entre os tratamentos.

O não aumento de consumo de azevém pelos animais do FS indica que pode ter ocorrido efetiva modulação do comportamento dos animais, sem que houvesse aumento de MS ingerida, acompanhada por redução simultânea do peso de bocado, que também participa da composição do consumo diário de forragem. Além disso, o acesso restrito à pastagem de azevém sugere que os animais não tiveram tempo suficiente para expressar a compensação na ingestão de MS. 
Quando se reduz o tamanho de bocado, independentemente do evento que o originou, o animal pode aumentar a frequência de bocados ou o tempo de pastejo para compensar a redução de consumo por bocado, sem, no entanto, obter incremento de consumo ou mesmo impedir o seu declínio (Gontijo Neto et al., 2006). O aumento no tempo e na frequência de bocados acaba por originar diminuição no peso do bocado por estar, na maioria das vezes, relacionado a incremento do esforço de seleção da dieta.

Os animais que pastejaram o trevo-branco como forma alternativa de suplementação proteica mostraram que, em pastejo rotativo em faixas com tempo de permanência restrito, a ingestão de azevém se faz de um modo mais eficiente, provavelmente porque eles consumiram a mesma quantidade de proteína que os do outro grupo, o que é explicado pela produção leiteira, muito semelhante na avaliação - 13,57 e 13,31 litros vaca $^{-1}-$, respectivamente, para o TB e o FS.
Na Fig. 1, mostra-se a atividade de pastejo segundo os grupos. Observa-se que, em cada intervalo de registro de atividades - de 10 minutos - do final do período de pastejo, mais aparentemente a partir do intervalo 10h55-11h05, o tempo de duração das refeições - em minutos por animal - permaneceu maior para o FS. Os animais que receberam dieta com menor teor de fibra foram obrigados a passarem mais tempo pastejando na tentativa de ajustar sua ingestão de MS, sem, no entanto, haver um aumento. Este fato não ocorreu com os animais que tiveram acesso à pastagem de trevo-branco, que apresentaram maior intervalo entre refeições, pelo menor tempo em pastejo nos intervalos, em razão de terem mais tempo de acesso à pastagem durante o dia e, provavelmente, terem expressado maior tamanho de bocado. Apesar de as vacas serem altamente consistentes quanto ao tempo despendido para alimentação, conforme DeVries et al. (2003), outros meios de comportamento podem ser usados para ajudar sua ingestão diária de MS.

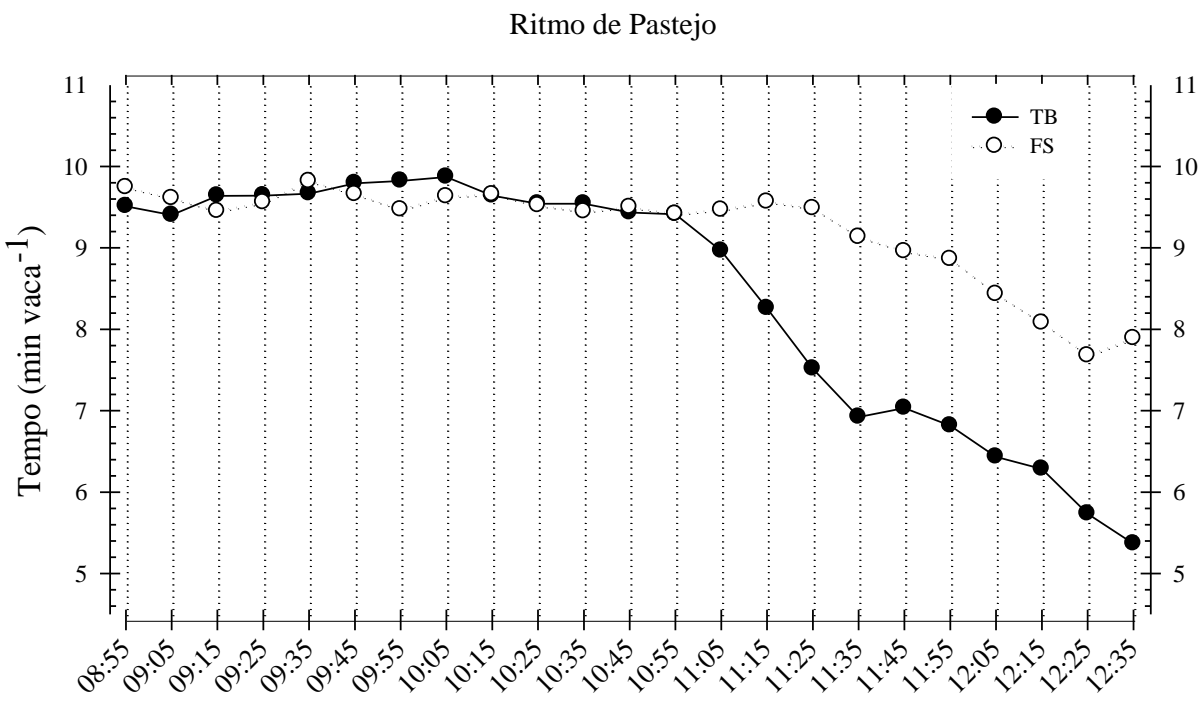

Intervalo (10 min)

Figura 1. Tempo em atividade de pastejo nos tratamentos trevo-branco (TB) e farelo de soja (FS), ao longo do período de pastejo em azevém, média de cinco avaliações.

De acordo com Baggio et al. (2008), o animal transmite sinais, via comportamento ingestivo, sobre a abundância e qualidade de sua alimentação, principalmente quando em ambiente pastoril, que, se utilizado para ponderar ações de manejo, pode se tornar uma importante ferramenta de gestão do animal no pasto. Pode-se inferir que as vacas leiteiras apresentaram diferente comportamento alimentar em pastejo de azevém, em resposta às formas de suplementação proteica, mostrando que modulam seus hábitos. Isso permite uma melhor adaptação ao ambiente de criação, o que pode resultar na manutenção, ou até melhoria, da expressão de seu potencial produtivo 
Deste modo, conforme os resultados obtidos no experimento, o pastejo de trevo-branco como aporte proteico às vacas em substituição ao farelo de soja surge como uma importante alternativa de manejo alimentar na proposição de sistemas de produção leiteira mais sustentáveis.

\section{CONCLUSÕES}

A utilização de pastagem de trevo-branco como fonte alternativa de alimentação proteica de vacas da raça Holandesa é tecnicamente viável e eficiente.

\section{AGRADECIMENTOS}

À prefeitura Municipal de Camargo/RS, ao CNPq e ao Condomínio Nova Era, pela viabilização financeira e pelo apoio na execução do experimento.

\section{REFERÊNCIAS}

BAGGiO, C.; CARVALHO, C.F.C.; SILVA, J.L.S. et al. Padrões de uso do tempo por novilhos em pastagem consorciada de azevém anual e aveia-preta. Rev. Bras. Zootec., v.37, p.1912-1918, 2008.

BARGO, F.; MULLER, L.D.; KOLVER, E.S. et al. Production and digestion of supplemented dairy cows on pasture. J. Dairy Sci., v.86, p.1-42, 2003.

CURTIS, S.E.; HOUPT, K.A. Animal ethology: its emergence in animal science. J. Anim. Sci., v.57, p.234-247, 1983.

DeVRIES, T.J.; Von KEYSERLINGK, M.A.G.; BEAUCHEMIN, K.A. Short comunication: diurnal feeding pattern of lactating dairy cows. $J$. Dairy Sci., v.86, p.4079-4082, 2003.

GONTIJO NETO, M.M.; EUCLIDES, V.P.B.; NASCIMENTO Jr., D. et al. Consumo e tempo diário de pastejo por novilhos Nelore em pastagem de capim tanzânia sob diferentes ofertas de forragem. Rev. Bras. Zootec., v.35, p.60-66, 2006.

GRANT, R.J.; ALBRIGHT, J.L. Feeding Behaviour. In: D'MELLO, J.P.F. (Ed.). Farm Animal Metabolism and Nutrition. Wallingford: CABI, 2000. p.365-382.
IMAIZUMI, H.; SANTOS, F.A.P.; BITTAR, C.M.M. et al. Diet crude protein content and sources for lactating dairy cattle. Sci. Agric., v.67, p.16-22, 2010.

IPAGRO. Seção de Ecologia Agrícola. Atlas agroclimático do Estado do Rio Grande do Sul. Porto Alegre: Secretaria da Agricultura, 1989. $210 \mathrm{p}$.

JAMIESON, W.S.; HODGSON, J. The effect of daily herbage allowance and sward characteristics upon the ingestive behavior and herbage intake of calves under strip-grazing for grazing dairy cows. Grass Forage Sci., v.34, p.69-77, 1979.

LIMA, R.M.B.; FERREIRA, M.A.; BRASIL, L.H.A. et al. Substituição de milho por palma forrageira: comportamento ingestivo de vacas mestiças em lactação. Acta. Sci. Anim. Sci., v.25, p.347-353, 2003.

MENDONÇA, S.S.; CAMPOS, J.M.S.; VALADARES FILHO, S.C. et al. Comportamento ingestivo de vacas leiteiras alimentadas com dietas à base de cana-de-açúcar ou silagem de milho. Rev. Bras. Zootec., v.33, p.723-728, 2004.

OLIVEIRA, M.A.; REIS, R.B.; LADEIRA, M.M. et al. Produção e composição do leite de vacas alimentadas com dietas com diferentes proporções de forragem e teores de lipídeos. Arq. Bras. Med. Vet. Zootec., v.59, p.759-766, 2007.

PATIÑO PARDO, R.M.; BALBINOTTI, M.; FISCHER, V. et al. Comportamento ingestivo diurno de novilhos em pastejo submetidos a níveis crescentes de suplementação energética. Rev. Bras. Zootec., v.32, p.1408-1418, 2003.

PEDROSO, A.M.; SANTOS, F.A.P.; BITTAR, C.M.M. Substituição do milho em grão por farelo de glúten de milho na ração de vacas em lactação em confinamento. Rev. Bras. Zootec., v.38, p.1614-1619, 2009.

PEREIRA, L.M.R.; FISCHER,V.; MORENO, C.B. et al. Comportamento ingestivo diurno de novilhas Jersey em pastejo recebendo diferentes suplementos. Rev. Bras. Agrociência, v.11, p.453-459, 2005.

PILLAR, V.P. (Ed.). Multiv: Multivariate Exploratory Analysis, Randomization Testing and Bootstrap Resamplimg. User's Guide. Porto Alegre: UFRGS, 2006. 51p. 
PINA, D.S.; VALADARES FILHO, S.C.; VALADARES, R.F.D. et al. Consumo e digestibilidade aparente total dos nutrientes, produção e composição do leite de vacas alimentadas com dietas contendo diferentes fontes de proteína. Rev. Bras. Zootec., v.35, p.1543-1551, 2006.
SANTILLAN, R.A.; OCUMPAUGH, W.R.; MOTT, G.O. Estimating forage yield with a disk meter. Agron. J., v.71, p.71-74, 1979.

VAN SOEST, P.J. Nutritional ecology of the ruminant. Ithaca: Cornell University, 1994. 476p. 